\title{
Surgical Management of Lumbar Spinal Stenosis in Patients Over 80 : Is There an Increased Risk?
}

frédérick rault ( $\square$ freddydo@hotmail.fr)

CHU Caen: Centre Hospitalier Universitaire de Caen https://orcid.org/0000-0001-5291-0952

Anaïs R Briant

2Unité de Biostatistique et Recherche Clinique (UBRC)

Thomas Gaberel

Caen University Hospital

Hervé Kamga

Caen University Hospital

Evelyne Emery

Caen University Hospital

\section{Research Article}

Keywords: Lumbar spinal stenosis, Complication, The elderly, Comorbidities

Posted Date: November 19th, 2021

DOI: https://doi.org/10.21203/rs.3.rs-1017167/v1

License: @ (1) This work is licensed under a Creative Commons Attribution 4.0 International License. Read Full License

Version of Record: A version of this preprint was published at Neurosurgical Review on March 3rd, 2022. See the published version at https://doi.org/10.1007/s10143-022-01756-w. 


\section{Abstract}

Introduction:

Management of lumbar spinal stenosis (LSS) represents the first cause of spinal surgery for the elderly and will increase with the aging population. Although the surgery improves quality of life, the procedure involves anaesthetic and operative risks. The aim of this study was to assess whether the postoperative complications rate was higher for elderly patients and to find confounding factors.

Material and Methods

We conducted a retrospective study including all LSS surgeries between 2012 and 2020 at the University Hospital of Caen. We compared two populations opposing patients aged over 80 with others. The primary endpoint was the occurrence of a severe complication (SC). Minor complications were the secondary endpoint. Comorbidities, history of lumbar spine surgery and surgical characteristics were recorded.

Results

996 patients undergoing surgery for degenerative LSS were identified. Patients over 80 were significantly affected by additional comorbidities: hypertension, heart diseases, higher age-adjusted comorbidity Charlson score, ASA score and use of anticoagulants. Knee-chest position was preferred for younger patients. Older patients underwent a more extensive decompression and had more incidental durotomies. $5.2 \%$ of patients presented SC. Age over 80 did not appear to be a significant risk factor for SC, but minor complications increased. Multivariate analysis showed that heart diseases, history of laminectomy, AA-CCl, and accidental durotomies were independent risk factors for SC.

Conclusion

Surgical management for lumbar spinal stenosis is not associated to a higher rate of severe complications for patients over 80 years of age. However, preoperative risk factors should be investigated to warn the elderly patients that the complications risk is increased although an optimal preparation is the way to avoid them.

\section{Introduction}

\section{Demographic evolution in France}

Neurosurgical practice will naturally evolve with the demographic changes. Indeed, an aging population has been observed for several years in France. In 2020, the National Institute of Statistics and Economic Studies (INSEE) reported an increasing number of people aged over 65 years old: $15 \%$ in 2000 compared to $20 \%$ in 2020 [1]. This social trend is more pronounced in Normandy, a northwest region of France, where an increasing number of retirees lives. By 2050 , the INSEE forecasts an inflation for the seniors of $37 \%$ and of $127 \%$ for the over 80 s in Normandy [58], while the number of dependent persons will increase by $50 \%$ [59]. Consequently, geriatric pathologies will represent most of the neurosurgical activity.

\section{Lumbar spinal stenosis: a usual pathology for Neurosurgeons}

Lumbar spinal stenosis (LSS) is defined by the North American Spine Society (NASS) as "the narrowing of the vacant space for the roots of the equina cauda and their vessels in the lumbar spine due to degenerative processes" [26]. Neurologic claudication in the legs exacerbated when walking and decreased when sitting is a typical symptom of LSS. This condition affects $8-23 \%$ of patients suffering from low back pain [19] and is the number one spinal surgery in the US for seniors [9]. In France, LSS accounted for 24737 hospitalizations in 2019 and is a frequent cause of consultation [60]. The LSS remains a classic geriatric condition leading to dependency and weakness in the elderly [5] [34] [35].

\section{The balance risk/benefit}

The surgery offers an advantage over nonsurgical management for selected individuals suffering from LSS and disabling symptoms [51]. The surgical technique is based on posterior decompression of the lumbar canal with a laminectomy and a bilateral foraminotomy with or without fusion.

However, patient's age and comorbidities may impact the invasiveness of the surgery and affect the risk-benefice balance. Many studies have attempted to assess the potential increased risk for older patients, but their results were different [32] [16]. The aim of our study was to find out whether patients over 80 years have an increased risk of developing postoperative complications and to identify risk factors.

\section{Materials And Methods}


We conducted a single-centre retrospective study at the University Hospital of Caen in the neurosurgical unit.

All patients admitted for a planned surgery of LSS between 2012 and 2020 were included. We used the surgical planning software to include patients according to precise surgical criteria (classical lumbar laminectomy with foraminotomy, segmental arthrodesis no more than one level, mini-invasive decompression surgery with interspinous device or unilateral foraminotomy). It was decided to exclude aggressive surgical procedures such as: scoliosis correction, interbody fusion and posterolateral arthrodesis affected at least two-level. The study obtained the consent of the ethic committee of the French College of Neurosurgery (showed in appendices).

Two groups were formed: the over 80 s versus the under 80 s. 80 was the chosen limit, that of the 4th age[1] where the risk of postoperative complications is theoretically higher.

\section{Outcomes}

The primary outcome was the occurrence of severe complications within the 30 days following the surgery.

A severe complication was defined as death, intensive-care unit hospitalization, reoperation, severe organ failure. The secondary outcome was the occurrence of minor complications, including sepsis, thrombosis without pulmonary emboly (PE), transfusions, urinary retention, or abdominal occlusion, and rehospitalizations within the 30 days after discharge.

\section{Variables}

We retrospectively recorded patient characteristics from the medical records. We reported:

- Demographic data: age, sex

- Body mass index (BMI)

- Comorbidities described during the pre-anaesthetic consultation: diabetes mellitus, high blood pressure, heart diseases (valvulopathy, arrhythmia, myocardial infarction or angina pectoris, hypertrophic heart disease, heart transplantation and congestive heart failure), breathing disorders (chronic obstructive pulmonary disease, severe asthma, severe sleep apnea) and chronic kidney disease

- Medication: anticoagulants and platelet antiaggregants

- ASA score and age-adjusted Charlson Comorbidity index ( $\mathrm{Cl})$ [7]. The $\mathrm{CCl}$ is widely used in the spine literature to evaluate postoperative risk in relation to comorbidities [45].

- Medical history of lumbar spinal surgery

- Presence of scoliosis or degenerative spondylolisthesis (DS)

- Surgical procedures: position, length of the surgery, number of decompressed levels, technique, use of a drain in the surgical site, and incidental durotomy.

\section{Statistical analysis}

The baseline characteristics were described by the mean (std) or the median (IQR) for quantitative variables according to their distribution and by the number (frequency) for qualitative variables. The two groups were independent. The comparisons of these variables between the age groups were performed using the Student's t-test or the Mann-Whitney test for quantitative variables giving to their normal distribution or not. We performed the $\mathrm{Chi}^{2}$ test or the Exact Fisher test for qualitative variables. To identify potential risk factors of severe complications up to 30 days, univariate analyses were performed using logistic regression. All significant variables associated with serious complications on univariate analysis $(p<0.05)$ were considered for inclusion in the multivariate logistic regression analysis. We explored collinearity among these potential risk factors by calculating the variance inflation factor (VIF), with a value above 5 indicating collinearity. We followed a backward procedure among qualified variables for selecting independent risk factors associated with severe complications, with the threshold of $p<0.10$ to stay in the model. Only our variable of interest, the age group, was included in every model. The minor complications and the length of hospitalisation were compared between the age groups using the Chi ${ }^{2}$ test and the Mann-Whitney test, respectively.

A sensitivity analysis was performed using the propensity score matching method to take into account the potential channelling bias on the endpoints. We modelled the probability of being $\geq 80$ years old implementing a non-parsimonious logistic regression including the following variables: sex, BMI, diabetes, high blood pressure, heart diseases, anticoagulants, platelet antiaggregants, breathing disorders, chronic kidney diseases, Charlson comorbidity index, ASA Score, history of lumbar surgery, herniated disc, spondylolisthesis, scoliosis, operative position, time, number of operating levels, L4L5, L3L4, L2L3, L1L2, laminectomy, foraminotomy, arthrodesis, interspinous spacer, durotomies, sutured, patch of fat to overcome the gap, organic glue, setting up a drain in suction (Showing in the appendices: Odds Ratios with $95 \%$ Wald Confidence Limits). We performed a one-to-one procedure (macro ONETOMANY) to match age groups based on their propensity score. Next, we analysed this 
paired population adopting the generalized linear model with the binomial distribution. Baseline characteristics were compared between groups before and after the matching procedure exploiting the standardized average differences.

All analyses were conducted in the thorough case analysis. A p-value less than 0.05 was considered significant; all p values were two-tailed. Statistical analysis was performed with SAS software V9.4 (SAS institute, NC, Cary) and R software, version 4.0 .5 (the R Foundation for Statistical Computing).

\section{Results}

\section{Cohort}

From 2012 to 2020, we included 1409 surgical procedures for lumbar spine stenosis in the neurosurgical unit of the University Hospital of Caen and 413 patients were excluded (figure 1). The mean age was 71.2 years. The over 80 s represented $20.4 \%$ of patients. The youngest patient was 38 years old and the oldest was 99 . Considering the sex ratio, $53.2 \%$ of the patients were women. The oldest age group contained significantly more women (61\% vs $51 \%$ p=0.019, Table 1$)$.

\section{Comorbidities (table 1)}

The mean BMI was $28.4 \mathrm{~kg} / \mathrm{m}^{2}(+/-5.12)$ and the elderly had on average a significantly lower BMI $\left(27.2 \mathrm{~kg} / \mathrm{m}^{2} \mathrm{vs} 28.7 \mathrm{~kg} / \mathrm{m}^{2}, \mathrm{p}<0.001\right)$. High blood pressure was the main comorbidity for $60 \%$ of the patients and the elderly were more affected. Patients over 80 years of age presented significantly more heart diseases and use of anticoagulants. Age adjusted CCI and ASA score were higher for these patients. The rate of diabetes was $17.8 \%$ and this disease mainly affected the youngest patients, but no statistical difference was found as for breathing disorders and CKD.

\section{Table 1: Comorbidities}

\begin{tabular}{|lllc|}
\hline Comorbidities & $\begin{array}{c}<80 \\
(\mathbf{n = 7 9 3})\end{array}$ & $\begin{array}{c}\geq 80 \\
(\mathbf{n = 2 0 3})\end{array}$ & $\mathbf{p}$ \\
\hline BMI $\left(\mathrm{kg} / \mathrm{m}^{2}\right)$, mean $\pm \mathrm{SD}$ & $28.7 \pm 5.1$ & $27.2 \pm 5.0$ & $<0.001$ \\
\hline Female, $\mathrm{n}(\%)$ & $407(51)$ & $123(61)$ & 0.019 \\
\hline Diabetes, $\mathrm{n}(\%)$ & $146(18)$ & $31(15)$ & 0.310 \\
\hline High blood pressure, $\mathrm{n}(\%)$ & $446(56)$ & $141(69)$ & $<0.001$ \\
\hline Heart disease, $\mathrm{n}(\%)$ & $179(23)$ & $78(39)$ & $<0.001$ \\
\hline Anticoagulant, $\mathrm{n}(\%)$ & $50(6)$ & $33(16)$ & $<0.001$ \\
\hline Platelet Antiaggregant, $\mathrm{n}(\%)$ & $227(29)$ & $68(34)$ & 0.169 \\
\hline Breathing disorder, $\mathrm{n}(\%)$ & $104(13)$ & $19(9)$ & 0.147 \\
\hline CKD, $\mathrm{n}(\%)$ & $29(4)$ & $10(5)$ & 0.408 \\
\hline Age Adjusted Charlson comorbidity index, median (IQR) & $3(2-4)$ & $4(4-5)$ & $<0.001$ \\
\hline ASA Score, median (IQR) & $2(2-3)$ & $3(2-3)$ & $<0.001$ \\
\hline
\end{tabular}

$B M I$, body mass index; $C K D$, chronic kidney disease; IQR, interquartile range; $S D$, standard deviation.

p-value obtained by chi ${ }^{2}$ or Fischer's exact test for qualitative variables, and by Student's t test or Mann-Withney test if the distribution does not follow a normal distribution, for quantitative variables.

\section{Surgical characteristics (table 2)}

A history of lumbar spinal surgery was present in $13.8 \%$ of cases with no difference between the two classes studied. Regarding the morphology of the lumbar spine, $23.2 \%$ of the patients were affected by a degenerative spondylolisthesis DS and $9,7 \%$ by a degenerative scoliosis in the entire cohort. The rate of scoliosis was higher in the elderly whereas the rate of DS was equivalent.

In most cases (72\%), patients were positioned in knee-chest. This position was more used in younger patients and the prone position was predominant in the elderly ( $43 \%$ vs $24 \%$, p 0.001 ). $63.5 \%$ of patients underwent laminectomy with bilateral foraminotomy without fusion as a decompression technique. This technique was more commonly realized in older patients ( $81 \%$ vs $59 \%$, p $<0.001)$. The most decompressed level 
was L4L5. The number of decompressed levels was higher in the elderly group $(p<0.001)$. We found a statistical difference for the levels $L 4 L 5$, L3L4, L2L3, and L1L2, which were more decompressed in the elderly group. Posterolateral arthrodesis was performed in $22.2 \%$ of cases, mainly in young subjects $(24 \%$ vs $16 \%, p=0.02)$ as the use of interspinous devices $(11 \%$ vs $1 \%, p<0.001)$. Regarding the duration of surgery, it was similar between two groups. The rate of durotomies was higher in the elderly group. We found a rate of $17.3 \%$ in the entire cohort. Durotomies were treated with sutures in $53.2 \%$ of leakages, $60.7 \%$ with fat graft and $70.5 \%$ with biologic glue. In most cases, surgeons used drains (93.8\%). Finally, the average LOS was 5.8 days, and the elderly patients had a longer LOS showed by the median LOS ( 6 days vs 5 days, p<0.001; table 3).

\section{Table 2: Comparison of surgical characteristics}




\begin{tabular}{|c|c|c|c|}
\hline Surgical characteristics & $\begin{array}{l}<80 \\
(n=793)\end{array}$ & $\underset{(n=203)}{\geq 80}$ & $\mathbf{p}$ \\
\hline History of lumbar spinal surgery & $114(14)$ & $23(11)$ & 0.256 \\
\hline Disc herniation, $\mathrm{n}(\%)$ & $61(8)$ & $9(4)$ & 0.106 \\
\hline Laminectomy, n (\%) & $34(4)$ & $8(4)$ & 0.827 \\
\hline Interepinous spacer, n (\%) & $10(1)$ & $0(0)$ & 0.228 \\
\hline Arthrodesis, n (\%) & $21(3)$ & $7(3)$ & 0.524 \\
\hline Foraminotomy, n (\%) & $2(0.3)$ & $0(0.0)$ & 1.000 \\
\hline \multicolumn{4}{|l|}{ Radiological characteristics } \\
\hline Spondyloisthesis, n (\%) & $178(22)$ & $53(26)$ & 0.270 \\
\hline Scoliosis, n (\%) & $70(9)$ & $27(13)$ & 0.056 \\
\hline \multicolumn{4}{|l|}{ Position, n (\%) } \\
\hline Ventral (0) & $188(24)$ & $86(43)$ & \multirow[t]{2}{*}{$<0.001$} \\
\hline Knee-chest (1) & $601(76)$ & $116(57)$ & \\
\hline Length (min), median (IQR) & $82(63-107)$ & $84(70-113)$ & 0.071 \\
\hline \multicolumn{4}{|l|}{ Level } \\
\hline Number, median (IQR) & $1(1-2)$ & $2(1-2)$ & $<0.001$ \\
\hline L5S1, n (\%) & $40(5)$ & $11(5)$ & 0.832 \\
\hline L4L5, n (\%) & $615(78)$ & $174(86)$ & 0.011 \\
\hline L3L4, n (\%) & $424(53)$ & $135(67)$ & $<0.001$ \\
\hline L2L3, n (\%) & $115(15)$ & $41(20)$ & 0.048 \\
\hline L1L2, n (\%) & $8(1)$ & $7(3)$ & 0.020 \\
\hline \multicolumn{4}{|l|}{ Procedure } \\
\hline Laminectomy, n (\%) & $467(59)$ & $165(81)$ & $<0.001$ \\
\hline Discectomy, n (\%) & $22(3)$ & $4(2)$ & 0.630 \\
\hline Foraminotomy, n (\%) & $32(4)$ & $4(2)$ & 0.207 \\
\hline Arthrodesis, n (\%) & $189(24)$ & $33(16)$ & 0.020 \\
\hline Interspinous spacer, n (\%) & $91(11)$ & $2(1)$ & $<0.001$ \\
\hline Durotomy & $125(16)$ & $48(24)$ & 0.008 \\
\hline Sutured, n (\%) & $67(8)$ & $25(13)$ & 0.079 \\
\hline Fat graft, n (\%) & $79(10)$ & $26(13)$ & 0.223 \\
\hline Biologic glue, n (\%) & $91(12)$ & $31(15)$ & 0.131 \\
\hline Use of drain & $737(94)$ & $192(96)$ & 0.207 \\
\hline Drain in suction, n (\%) & $631(80)$ & $152(76)$ & 0.156 \\
\hline
\end{tabular}

p-value obtained by chi ${ }^{2}$ or Fischer's exact test for qualitative variables and by Student's t test, or Mann-Withney test if the distribution does not follow a normal distribution, for quantitative variables.

\section{Complications between the two groups (table 3)}

In our study, 52 severe complications were reported representing $5.2 \%$ of cases. Two patients aged of 77 and 79 years old died within thirty days after surgery. Three cases were admitted to ICU. Regarding the surgical procedure, $3.6 \%$ of patients underwent revision, and the main 
cause was a postoperative epidural hematoma. Among the 222 patients who had a segmental fusion, $3.6 \%$ had revisions for symptomatic pedicle screws malposition. Removal of drains was impossible for the nurses and required revision for two patients.

Regarding the medical management, 14 patients suffered from severe medical complications. We described two anaphylactic shocks, one severe pneumopathy with death, three hypovolemic shocks, two myocardial infarctions, one pulmonary embolism, one congestive heart failure, one acute respiratory failure due to Covid infection, one acute ischemic stroke with aphasia, one acute tubular necrosis and one cerebellar haemorrhage. Regarding minor events, $8 \%$ of patients had minor complications after surgery: sepsis was the main complication for $3 \%$ of cases. $0.9 \%$ of patients had a transfusion in postoperative period. $2.6 \%$ of patients were readmitted within 30 days of surgery.

\section{Table 3: Comparison of complications}

\begin{tabular}{|c|c|c|c|c|}
\hline Outcomes & $\begin{array}{l}\text { All } \\
(n=996)\end{array}$ & $\begin{array}{r}<80 \text { ans } \\
(n=793)\end{array}$ & $\underset{(n=203)}{\geq 80 \text { ans }}$ & $\mathbf{p}$ \\
\hline Severe complications, $\mathrm{n}(\%)$ & $52(5.2)$ & $38(4.8)$ & $14(6.9)$ & 0.229 \\
\hline Death & $2(0.2)$ & $2(0.3)$ & $0(0.0)$ & \\
\hline ICU admission & $3(0.3)$ & $2(0.3)$ & $1(0.5)$ & \\
\hline Revision surgery & $36(3.6)$ & $29(3.7)$ & $7(3.5)$ & \\
\hline Malposition of screws & $8(0.8)$ & $7(0.9)$ & $1(0.5)$ & \\
\hline Wound infection & $10(1.0)$ & $9(1.1)$ & $1(0.5)$ & \\
\hline Epidural hematoma & $17(1.7)$ & $12(1.5)$ & $5(2.5)$ & \\
\hline Trapped drain & $2(0.2)$ & $0(0)$ & $2(0.1)$ & \\
\hline CSF leakage (sutured, fat graft, biologic glue) & $6(0.6)$ & $6(0.8)$ & $0(0.0)$ & \\
\hline Severe medical complications & $14(1.4)$ & $7(0.9)$ & $7(3.5)$ & \\
\hline Minor complications n (\%) & $80(8.0)$ & $51(6.4)$ & $29(14.3)$ & $<0.001$ \\
\hline Phlebitis & $3(0.3)$ & $0(0.0)$ & $3(1.5)$ & \\
\hline Sepsis & $30(3.0)$ & $23(2.9)$ & $7(3.5)$ & \\
\hline Abdominal occlusion and urine retention & $25(2.5)$ & $13(1.6)$ & $12(5.9)$ & \\
\hline Transfusion & $9(0.9)$ & $4(0.5)$ & $5(2.5)$ & \\
\hline CSF leakage without surgery & $3(0.3)$ & $3(0.4)$ & $0(0.0)$ & \\
\hline Fracture & $2(0.2)$ & $2(0.3)$ & $0(0.0)$ & \\
\hline Confusion & $2(0.2)$ & $1(0.1)$ & $1(0.5)$ & \\
\hline Readmission & $26(2.6)$ & $22(2.8)$ & $4(2.0)$ & \\
\hline Length of stay (days), median (IQR) & $5(4-7)$ & $5(4-6)$ & $6(4-9)$ & $<0.001$ \\
\hline
\end{tabular}

ICU, intensive care unit; CSF, cerebrospinal fluid

p-value obtained by chi ${ }^{2}$ or Fischer's exact test for qualitative variables and by Student's t test, or Mann-Withney test if the distribution does not follow a normal distribution, for quantitative variables.

Table 6: Matching with propensity score

* $p$-value obtained by chi ${ }^{2}$ or Fischer's exact test for qualitative variables and by Student's $t$ test, or Mann-Withney test if the distribution does not follow a normal distribution, for quantitative variables 


\begin{tabular}{|c|c|c|c|c|c|c|}
\hline \multirow[b]{2}{*}{ Baseline characteristics } & \multicolumn{3}{|c|}{ Unmatched } & \multicolumn{3}{|c|}{ Matched } \\
\hline & $\begin{aligned} &<<80 \\
&(\mathrm{n}=793)\end{aligned}$ & $\begin{array}{c}\geq 80 \\
(\mathrm{n}=203)\end{array}$ & SMD & $\begin{array}{c}<80 \\
(\mathrm{n}=135)\end{array}$ & $\begin{array}{c}\geq 80 \\
(n=135)\end{array}$ & SMD \\
\hline Female, $n(\%)$ & $407(51)$ & $123(61)$ & 0.19 & $86(64)$ & $82(61)$ & 0.06 \\
\hline $\begin{array}{l}\mathrm{BMI}\left(\mathrm{kg} / \mathrm{m}^{2}\right), \mathrm{moy}=\mathrm{ET} \\
\text { Comorbidity }\end{array}$ & $28.7 \pm 5.1$ & $27.2 \pm 5.0$ & 0.31 & $27.3=4.4$ & $27.7 \pm 5.3$ & 0.08 \\
\hline Diabetes, $n(\%)$ & $146(18)$ & $31(15)$ & 0.08 & $23(17)$ & $23(17)$ & 0.00 \\
\hline High blood pressure, $n(\%)$ & $446(56)$ & $141(69)$ & 0.27 & $98(73)$ & $94(70)$ & 0.07 \\
\hline Heart diseases, $n(\%)$ & $179(23)$ & $78(39)$ & 0.35 & $44(33)$ & $50(37)$ & 0.09 \\
\hline Anticoagulants, $n(\%)$ & $50(6)$ & $33(16)$ & 0.32 & $16(12)$ & $19(14)$ & 0.07 \\
\hline Platelet antiaggregant, $n(\%)$ & $227(29)$ & $68(34)$ & 0.11 & $46(34)$ & $45(33)$ & 0.02 \\
\hline Breathing dis orders, n(\%) & 104 (13) & $19(9)$ & 0.12 & $9(7)$ & $11(8)$ & 0.06 \\
\hline Chronic kidney dis ease, $n(\%)$ & $29(4)$ & $10(5)$ & 0.06 & $7(5)$ & $8(6)$ & 0.03 \\
\hline Age adjusted Charls on Score, mediat & $3(2-4)$ & $4(4-5)$ & 1.12 & $4(3-5)$ & $4(4-5)$ & 0.09 \\
\hline AS A score, median (IQR) & $2(2-3)$ & $3(2-3)$ & 0.42 & $3(2-3)$ & $3(2-3)$ & 0.04 \\
\hline History of lumbar spine surgery & $114(14)$ & 23 (11) & 0.09 & $15(11)$ & $15(11)$ & 0.00 \\
\hline $\begin{array}{l}\text { Disc Herniation, } \mathrm{n}(\%) \\
\text { Morphology of the spine }\end{array}$ & $61(8)$ & $9(4)$ & 0.14 & $5(4)$ & $7(5)$ & 0.07 \\
\hline S pondylois thes is, $n(\%)$ & $178(22)$ & $53(26)$ & 0.09 & $30(22)$ & $36(27)$ & 0.10 \\
\hline S colios is, $n(\%)$ & $70(9)$ & $27(13)$ & 0.14 & $19(14)$ & $18(13)$ & 0.02 \\
\hline \multicolumn{7}{|l|}{ Surgery } \\
\hline \multicolumn{7}{|l|}{ Position, $n(\%)$} \\
\hline Prone $(0)$ & $188(24)$ & $86(43)$ & & $49(36)$ & $47(35)$ & \\
\hline Genv pectoral (1) & $601(76)$ & $116(57)$ & 0.41 & $86(64)$ & $77(65)$ & 0.03 \\
\hline $\begin{array}{l}\text { Time (minutes), median (IQR) } \\
\text { Levels }\end{array}$ & $82(63-107)$ & $84(70-113)$ & 0.14 & $87(72-106)$ & $84(70-113)$ & 0.08 \\
\hline Number, median (IQR) & $1(1-2)$ & $2(1-2)$ & 0.40 & $2(1-2)$ & $2(1-2)$ & 0.04 \\
\hline $\mathrm{L} 4 \mathrm{~L} \mathrm{~L}, \mathrm{n}(\%)$ & $615(78)$ & $174(86)$ & 0.21 & $114(84)$ & $114(84)$ & 0.00 \\
\hline $\mathrm{L} 3 \mathrm{~L} 4, \mathrm{n}(\%)$ & $424(53)$ & $135(67)$ & 0.28 & $82(61)$ & $83(61)$ & 0.02 \\
\hline $\mathrm{L} 2 \mathrm{~L} 3, \mathrm{n}(\%)$ & $115(15)$ & $41(20)$ & 0.15 & $31(23)$ & $26(19)$ & 0.09 \\
\hline $\operatorname{L} \mathbb{L} 2, \mathrm{n}(\%)$ & $8(1)$ & $7(3)$ & 0.17 & $4(3)$ & $4(3)$ & 0.00 \\
\hline Procedure & & & & & & \\
\hline Laminectony, $n(\%)$ & $467(59)$ & $165(81)$ & 0.50 & $105(78)$ & $105(78)$ & 0.00 \\
\hline Foraminotony, $n(\%)$ & $32(4)$ & $4(2)$ & 0.12 & $3(2)$ & $3(2)$ & 0.00 \\
\hline Arthrodesis, $n(\%)$ & $189(24)$ & $33(16)$ & 0.19 & $27(20)$ & $26(19)$ & 0.02 \\
\hline Interspinous device, $n(\%)$ & $91(11)$ & $2(1)$ & 0.45 & $3(2)$ & $1(1)$ & 0.12 \\
\hline CSF leakage & $125(16)$ & $48(24)$ & 0.20 & $27(20)$ & $30(22)$ & 0.05 \\
\hline Sutured, $n(\%)$ & $67(8)$ & $25(13)$ & 0.13 & $16(12)$ & $16(12)$ & 0.00 \\
\hline Fat graft, $n(\%)$ & $79(10)$ & $26(13)$ & 0.09 & $18(13)$ & $17(13)$ & 0.02 \\
\hline Biologic ghe, $n(\%)$ & $91(12)$ & $31(15)$ & 0.12 & $21(16)$ & $19(14)$ & 0.04 \\
\hline Drain & $737(94)$ & $192(96)$ & 0.11 & $129(96)$ & $130(97)$ & 0.08 \\
\hline In aspiration, $n(\%)$ & $631(80)$ & $152(76)$ & 0.11 & $105(78)$ & $106(79)$ & 0.02 \\
\hline Score de propension, movenne $\pm E$ & $0.12 \pm 0.17$ & $0.49 \pm 0.26$ & 1.67 & $0.39 \pm 0.22$ & $0.39 \pm 0.22$ & 0.02 \\
\hline
\end{tabular}

\section{Risk factors of complications}

An age over 80 did not appear to be a risk factor for SC because the difference between two classes was not significant in the multivariate analysis and with propensity score matching (table 4). However, age was identified as a risk factor in the univariate analysis (table 5). In addition, the rate of minor complications increased for the elderly: we noted more phlebitis, sepsis, abdominal obstructions and urinary retentions, and transfusions.

The length of stay was extended for the elderly, but the rate of readmissions was relatively similar between the two groups.

\section{Table 4: Relationship between two groups and severe complications}

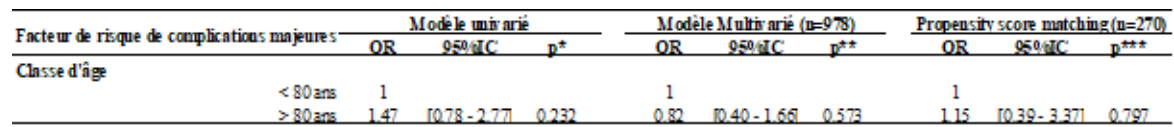

* p-value obtained by univariate logistic regression

** $p$-value obtained by multivariate logistic regression with stepwise downward selection and holding condition in the model fixed at 0.10 except for the variable of interest (age class) which was fixed in the model.

*** p-value obtained by generalized linear model with a binomial distribution and taking into account the matching

Regarding gender differences, we described that woman had more complications, but we did not find any statistically difference. Concerning the comorbidities, the presence of heart disease, breathing disorders, and platelet antiaggregants increased the risk of developing a SC. Anticoagulants and CKD did not appear to be risk factors. A higher ASA score and an age adjusted CCI were strongly associated with the development of SC. Even though these scores were higher in older patients, the age-adjusted CCI was an independent risk factor of the postoperative complication with a p-value significant in the multivariate analysis.

Scoliosis and a history of laminectomy was associated with increased postoperative complications. 
For the surgical features, the knee-chest position and a quick procedure seemed to decrease the risk of SC. We did not find any difference in SC related to the surgical procedure. The intraoperative durotomy was a high-risk factor for SC with a p-value of 0.002 . At the opposite the use of drains in suction prevented the occurrence of severe complications.

\section{Table 5: Risk factor of severe complications}

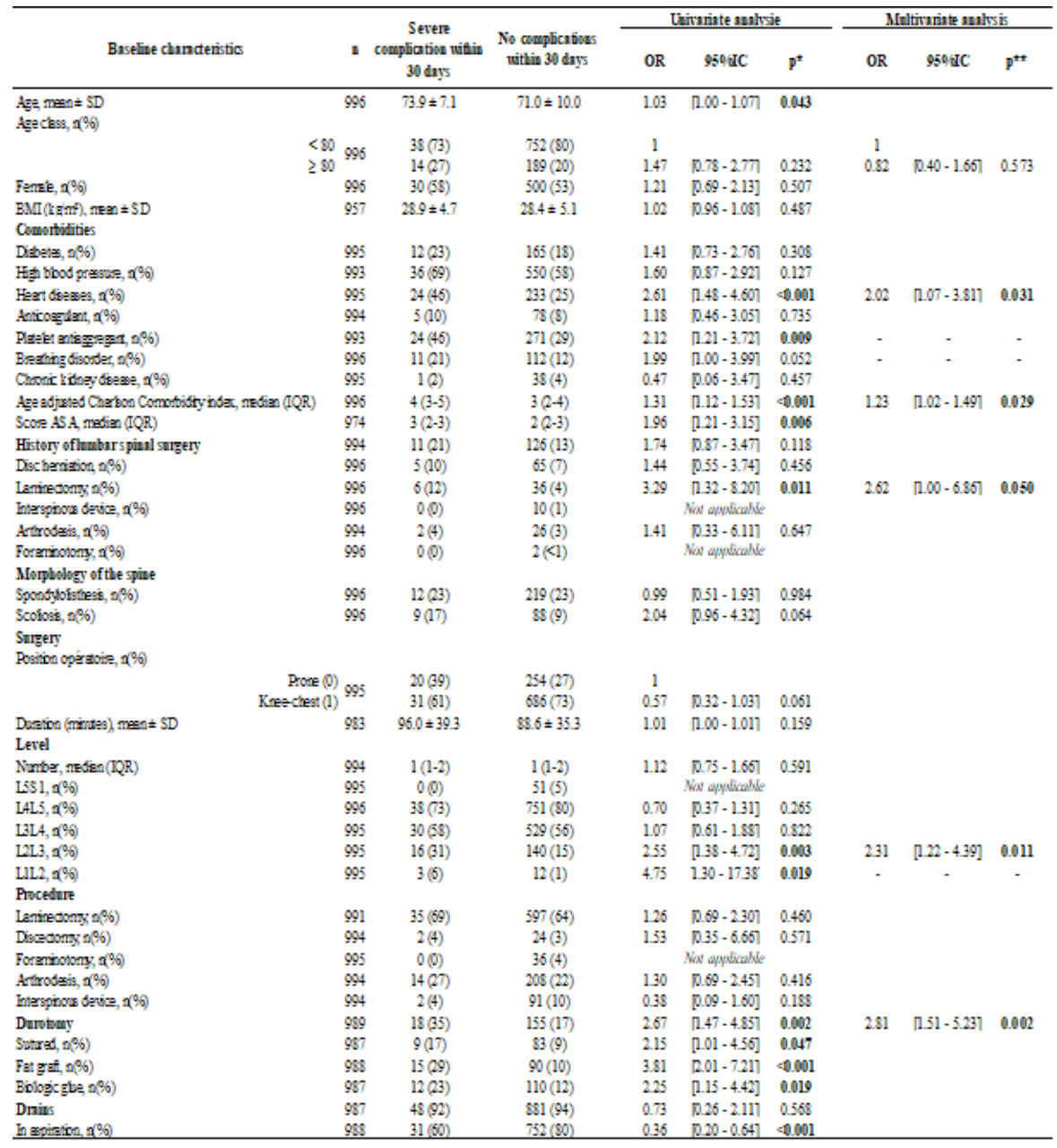

$B M$, body mass index; $\mathrm{CCl}$, Charlson Comorbidity Index, ${ }^{*} p$-value obtained by univariate logistic regression, ${ }^{*} p$-value obtained by multivariate logistic regression with stepwise downward selection and holding condition in the model fixed at 0.10 except for the variable of interest (age class) which was fixed in the model.

\section{Discussion}

\section{Main results}

In this study, we demonstrated that patients over 80 years of age were not at greater risk of developing a severe postoperative complication after surgery of lumbar spinal stenosis. Older patients had more comorbidities and the surgical procedure was different for this category. These parameters influenced the occurrence of a severe postoperative complication.

\section{Complications in elderly patients}

We found a $6.9 \%$ risk of SC within 30 days following LSS surgery for patients over $\mathbf{8 0}$ years of age. For patients over 80 s undergone LSS surgery, the complications rate is variable in the literature, according to the definition of a SC. Saleh et al [42]did a retrospective study in US based on national data with 2320 patients over 80 years of age. They found a lower risk of severe complications of $3.23 \%$. However, they did not include revisions as severe complications. Their SC corresponded to our severe medical complications with a similar rate: $3.5 \%$. Contrary to this study, we believe that a surgery revision should be considered as a severe complication. Another French study by Balabaud et al [2] showed a $13 \%$ rate of SC: they counted a higher epidural hematomas and wound infections rate of $3.3 \%$ and $4 \%$ (against $2.5 \%$ and $0.5 \%$ respectively for us). Their definition of severe medical complications was larger including new-onset cardiac arrhythmia and SIADH. Wang et al [50] made a 
same study with 26 patients over 85 years. Their complication rate was higher: $7.6 \%$ of SC. These observations continue to raise the question of the relationship between age and complications.

In our study, we showed that the risk of SC was not increased after surgical management of LSS in patients older than 80 . To compare Giannadakis et al [16] using the same design that us, showed that an age over 80 was not associated with increased complications. Murphy et al [32] made the same observation in a US national cohort of 8,744 patients divided into four classes: $<65,65-75,75-85,>85 Y 0$. They showed an increased complication rate for patients over 65 years of age. Dividing the cohort into several classes was interesting, nevertheless $58 \%$ of patients were under 65 years while the LSS mainly involved older people. Thus, our main question was to know whether in a group of seniors, the oldest patients were more likely to have complications. We also included patients under 65 , but they represented only $25 \%$. Li et al [29] published in 2008 the largest study on this topic with 471,215 patients. They found a direct association between the occurrence of complications and an age above 65. More interestingly, they showed an excess risk for people over 85 to develop a complication after a decompression of the lumbar spine.

Regarding complications in our cohort, the death rate was $0.2 \%$, but no patient died in the older group. Studies with young patients like the studies of Li et al [29] and Murphy [32] found a similar death rate. Studies including only elderly patients found a higher number: Gerhardt et al [13] reached a death rate of $0.8 \%$ while Saleh [42] found a rate of $0.4 \%$. Concerning admission to ICU, Kay et al [21] reported a 5.1\% rate after lumbar spinal surgery, more than ours: $0.3 \%$. However, they included more aggressive procedures: the rates of fusions and length of surgery were higher. In their study, female gender, ASA grade, cardiac comorbidities, age, length of surgery and blood loss were identified as risk factors for ICU admissions.

For unplanned readmissions, $2.6 \%$ of patients returned to the neurosurgical unit in our cohort. This rate is low compared to the literature: $6.39 \%$ for Saleh et al [42] with patients over 80 and 4.4\% found in the Kim et al study [61]. This last study showed that a high ASA score, venous thromboembolic events, re-operations in the first stay, post operative complications were risk factors. In our cohort, the rate of readmissions was similar between the older and younger groups. Murphy et al [32] found a higher readmission rate in older people compared to those under 65 , but they did not show evidence of an increased risk after 85 years old.

Concerning the LOS, older patients stayed longer in hospital as reported in the literature[32] [16]. Our median length of stay (five days for the youngest and six days for the oldest) could be improved with the introduction of the enhanced Recovery After Surgery: currently four days in hospital for the surgical management of LSS is our daily goal regardless of the age class.

\section{Management of comorbidities}

Beyond age, it seems that the postoperative outcome is related to several other factors. To start with the patient's comorbidities: we noticed that patients over $\mathbf{8 0}$ had higher $\mathrm{CCl}$ and ASA score meaning more comorbidities. To compare with the literature, the studies of Giannadakis [16] and Nanjo [33] found almost the same result (p-value at 0.09 and 0.07 respectively). In the study of Murphy et al [32], they showed an association between the increasing comorbidities and the aging excepted for high blood pressure. In our cohort, the elderly were significantly more affected by hypertension, the most frequent affection with $69 \%$ of cases. In France, hypertension is the leading cardiovascular risk factor. It increases with age and affects more than two-thirds of the population aged 65 to 75 years of age [62], consistent with our observations.

In our study, the risk of postoperative SC was independently related to heart diseases and to the use of antiaggregants. The management of anticoagulants and platelet antiaggregants must be a compromise between the risk of intraoperative blood loss or epidural hematoma and the risk of arterial thrombosis. Soleman et al [46] compared the impact of aspirin in 102 patients on the postoperative complications after LSS or herniated disc surgery. They showed no significant difference between the groups. However, they found higher blood loss, lower postoperative haemoglobin, more transfusions in the Aspirin group. Comparing with others studies, the rate of epidural hematoma varies between 0 to $1 \%$ [17]. Park et al [36] made a large retrospective study of 17,549 patients who undergone spinal decompression. They found a $1.15 \%$ rate of postoperative epidural hematoma. Risk factors were a high blood loss greater than $500 \mathrm{ml}$, a surgical duration greater than two hours, hypertension. The use of anticoagulants increases the risk, but the result was near significant. Anticoagulants were not considered as a risk factor of SC in our study. Our rate of thromboembolic events was similar to the literature : $0.2 \%$ for Ginnadakis [16], 0.5\% for Murphy [32], 0.4\% for Li [29]. In our study, the four patients concerned belonged to the elderly group. We did not perform a subgroup analysis for this risk factor although it appears that age may be a risk factor of thromboembolic events. This observation can be supported by Yoshioka's prospective study about thromboembolic events after degenerative spine surgery, which showed that advanced age was a risk factor [53].

Other comorbidities did not play a major role in the occurrence of SC. Regarding diabetes, this condition was slightly increased in patients with SC.. A large study based on data from the Korean National Health Insurance Service, showed that after surgery for LSS, the mortality rate was multiplied by 1.35 for diabetes patients [28]. The criteria of inclusion in the Korean study are less restricted than ours: no exclusion for aggressive surgical procedures. Furthermore, the result was significant in univariate analysis, but diabetic patients had more heart disease and chronic kidney disease which could impact the rate of severe complications. CKD did not appear as a risk factor of severe complications. To 
talk to diabetes again, its management must involve the anaesthesiologist. The SFAR recommends to look for its complications, to evaluate its control, and to follow the prescription of antidiabetic drugs [56]. The major risk of unbalanced diabetes is the surgical site infection [52].

Concerning the BMI for the elderly, the standards are different from those for the youth. We talk about undernutrition for patients whose BMI is under 21 and obesity when BMI is over 30. Undernutrition is a known risk for spinal infections and can multiplicate the risk by 2.3 [49]. Like in the study of Giannadakis et al[16], the BMI was significantly lower for the elderly in our cohort, but no link with SC was noticed. A recent Chinese study made by Kong et al [25] evaluated the impact of BMI on lumbar arthrodesis for elderly patients: they found that low BMI under $24 \mathrm{~kg} / \mathrm{m}^{2}$ increased the complication rates. The preoperative nutritional evaluation is a way to minimize these risks. This topic is included in our current protocol "enhanced recovery after surgery" and was described in the literature [8]. Patients are assessed by dieticians and receive nutrition therapy if necessary. The rate of serum albumin level was described in the literature to detect undernutrition: Iow albumin are associated with an increased risk of readmissions, mortality, length of stay, and mortality [63] [10]. This data was not available. As the undernutrition, obesity also presented risks. Giannadakis et al [15] found that obesity increases the duration of the surgery. In addition to being a risk factor for LSS [24], it rises postoperative complications in spine surgery [4] especially for spinal infections. Beside obesity, other risk factors for wound infections have been described in the literature: blood loss, reoperation, diabetes, duration of the surgery and length of stay at hospital [55]. Age over $\mathbf{8 0}$ was not found to be a risk factor of wound infection in our study.

Regarding breathing disorders, no difference was observed between the two groups. These diseases appeared as a risk factor for complications with a p-value close to $\mathbf{0 . 0 5}$. Our broad definition of breathing disorders would allow us to detect a possible risk factor that was not described in the literature. To go on, this study did not evaluate the impact of smoking on SC. Giannadakis et al [16] found that the proportion of smokers was lower in the older group, but their did not find an increased risk of complications in LSS surgery. Smoking is known to be a risk factor for surgical site infections [18]. It is a target of our enhanced recovery after surgery program, as described in the literature [8].

\section{Performing the least morbid surgery?}

We have shown in our study that surgical procedures have an impact on the risk of SC. This highlights the issue of the invasiveness of the surgery. We need to propose the least risky surgery with the best benefit-risk ratio. This starts with the selection of the best operative position. In our cohort, the knee-chest position was the most used position for the management of LSS. Some compression complications, unfound in our cohort, have been described in the literature, such as blindness due to eyeball support, limb paralysis and shoulder dislocation [44]. Elderly patients were less likely to be positioned in knee-chest for hemodynamic reasons. The knee-chest position decreases the cardiac ejection fraction due to lack of venous return. It theoretically affects the elderly, who are more likely to suffer from heart disease. This position can lead to hypotension during surgery, which can cause strokes and acute renal failures [6]. However, this position is interesting for the surgeon: this hypotension reduces epidural blood loss during laminectomy and facilitates decompression by reducing the lordosis [41] leading to faster surgical procedures. In our cohort, the knee-chest position seemed to have a protective effect on the occurrence of serious postoperative complications.

Secondly, regarding durotomy, its rate varies in the literature between 0.5 and $18 \%$ [23]. In our study, the occurrence of a durotomy represented a strong risk factor for severe complications. Its rate was high: 17.3\%. The Swedish study of Strömqvist et al [47] evaluated the risk factors for the occurrence of durotomy in 64,431 patients. They found that age and history of lumbar spinal surgery were risk factors. In our cohort, older patients had significantly more durotomies, as shown in the literature [16]. In addition, they have undergone a significantly more extensive decompression that increases the risk to make a durotomy. Anatomically, during LSS decompression, most durotomies occur in the medial part of the joint [48], where the enlarged ligament sticks [47] especially for the elderly. Lateral durotomies can be delicate to suture, however no patient over 80 underwent a revision for CSF leakage. Another study from USA [22] with 766 patients showed a risk of durotomy of 19\% in patients over 65 years old. In practice, durotomy will result in the confinement to bed of the patient for 48 hours. This bed rest can cause complications as confusion for the elderly patients. Concerning confusions, its rate was very low and we think that we had a bias of information due to a lack of data in medical records. The rate of confusion after lumbar spinal surgery is variable in the literature: 0.8 $13 \%$ [25] [33] [2]. Increased age was found as risk factor in a large study of 578,457 lumbar decompressions [11]. Pernik et al [37] study the impact of geriatric optimization before spinal surgery on the postoperative delirium. Patients with geriatric assessment were older and had more comorbidities, but they had less delirium in postoperative time. Involving geriatricians in our care could therefore be a way to reduce minor complications for the oldest patients. Finally, Balabaud et al [2] found an association between instrumentation and the occurrence of delirium.

The question of whether an additional arthrodesis in the elderly should be performed is still being debated. We included in our study only arthrodesis with one level. The WNFS recommends a decompression alone if the patient has a predominantly radicular pain without signs of instability or with stable spondylolisthesis [43]. In our cohort, the prevalence of spondylolisthesis was $23 \%$. The prevalence of degenerative spondylolisthesis was determined in the Kalichman et al. study using the Framingham cohort [20]: $16 \%$ for patients over 70 and $16 \%$ for patients with low back pain. The use of fusion depends on the preoperative evaluation on the X-ray and on the search for instability [27]. Regarding grade 1 spondylolisthesis, Blumenthal et al [3] described the criteria for instability: sagittal facet joints with an angle $>50^{\circ}$, a disc

Page $11 / 16$ 
height greater than $6.5 \mathrm{~mm}$, and a mobile spondylolisthesis of more than $1.25 \mathrm{~mm}$ on dynamic X-ray. In addition, it is recognised that arthrectomy or isthmus resection creates postoperative instability [30]. In our study, these criteria were not available in all hospital records. Our philosophy on LSS and fusions is to follow guidelines while remaining as minimally invasive as possible. We have to keep in mind that fusion does not improve the functional status at two and five years and increases the blood loss and surgical costs [12]. In our study, fusions were not a risk factor to develop SC. We reported an occurrence of symptomatic screw malposition of $3 \%$ comparing with $10 \%$ in mean in the literature [14]. These results can be explained by the fact that we excluded patients with posterolateral arthrodesis more than one level. Saleh et al [42], who did not apply these criteria, found a complication rate twice as high in patients with arthrodesis. The sparing use of fusion reduces the risk of postoperative complications.

Then, the number of decompressed levels was greater in elderly subjects. Contrary to Murphy et al [32], we did not detect the number of levels as a major complications factor. The length of the surgery was also reported as a risk factor in their study. For Saleh et al [42], procedures lasting over 180 minutes presented an extra risk. In our cohort, only 1.8\% procedures lasted over 180 minutes. Kong et al [25] reported decompression as risk factor from three levels. In our study, only 46 patients had a more than three levels extension decompression, showing our desire to be less invasive. Continuing with the use of minimally invasive surgery, $9.3 \%$ of patients underwent the installation of interspinous device, allowing correction of the hyperlordosis responsible for radicular pain. 9.3\% of patients underwent this technique. However, the disadvantage of this technique is its efficiency. Indeed, the decompression may be insufficient with a reoperation rate of up to 27\% [54].

Finally, a more aggressive procedure may be related to increased blood loss during the operation. The postoperative red blood cell transfusion rate was $0.9 \%$ in our study. Giannadakis et al. [16] found an almost similar rate of $1.2 \%$ in their cohort. Our transfusion rate was higher in the elderly, but no subgroup analysis was performed in this study. ASA grade, duration of surgery and multilevel fusion were known risk factors of blood transfusion in the study of Morcos et al. [31] while age did not appear as a risk factor. They did not study the potential association between the operative position of the patient and transfusion. In our study, among nine transfused patients, five were positioned in prone position (55.6\%). As we have seen previously, this position could potentially increase blood loss and postoperative transfusions. Only one study by Rigamonti et al [39] was found in the literature. With only 30 patients undergoing microdiscectomy they compared prone vs knee-chest positions and their impact on blood loss. They reported significantly increased blood loss with knee-chest position. However, when the kneechest position was contraindicated due to cardiac or renal or respiratory disorders, patients were excluded. Moreover, microdiscectomy frequently involved younger patients with a mean age around 50, not comparable with our cohort. To avoid post-operative transfusions in lumbar spinal surgery, some authors reported the use of tranexamic acid before procedure. This drug should be used with caution in the elderly. CKD, epilepsy, venous and arterial thrombosis contraindicate its use [64]. In addition, minimally invasive techniques reduces intraoperative blood loss [38]. Finally, the search for preoperative anaemia may also have an impact on the transfusion rate. This is a target of our ERAS program: patients with anaemia receive an iron infusion or erythropoietin.

\section{Limitations}

We must point out some boundaries of our study. First, the retrospective design of the study may cause bias. Even though we are in a university hospital, we have to note that the anaesthesia team has performed a first screening of our patients. They rejected patients deemed unfit to receive general anaesthesia, which defines a selection bias in our population.

Secondly, the use of propensity score was very helpful to guarantee a good comparison between groups. It should be highlight that the standardized mean differences were 0.12 for an interspinous device (see table in appendix) and must keep between - 0.10 and 0.10 to have good comparison. 0.12 is very close to 0.10 and we considered with statisticians that the model can still be used. Next,

In severe complications, we chose to include the occurrence of severe organ failure. The definition of organ failure can be confusing. These complications are life-threatening for the patient and therefore we have included them.

Thirdly, the age limit of 80 years is an arbitrary limit. Even though it is used frequently in the literature, we find that physiological age is more important than chronological age. For a future study, we could have separated into 2 groups the patients considered fragile versus the others by evaluating the frailty. This corresponds to the reduction of physiological reserves through a multi-organ system that decreases resistance to stress [40]. We can measure this parameter with Fried's criteria. The review done by Simcox et al [45] showed a link between frailty and postoperative mortality, postoperative complications, and the risk of prolonged hospitalization. Concerning the impact of heart diseases on postoperative prognosis, anaesthetic score like MET or Lee were interesting to study this link.

Finally, it would be interesting to compare the complication rate per year. This would show the impact of new anaesthesia techniques such as locoregional anaesthesia and new surgical techniques such as the use of minimally invasive surgery.

\section{Conclusion}


To conclude, an age over 80 does not lead to higher surgical morbidity. Multidisciplinary management with the anaesthetist, geriatricians and other specialities seems essential to avoid the occurrence of postoperative complications.

Operating on increasingly fragile patients, the neurosurgeon must warn his patients of the potential risks associated with his comorbidities, previous surgeries, and the procedure itself. Indeed, we have detected many risk factors in this study. Enhanced recovery after surgery is potentially a useful tool to prevent from complications by correcting risk factors. It would be interesting to evaluate its usefulness in elderly patients.

For the future, some risk factors should be detailed to better target the conditions in preoperative care.

\section{Declarations}

Funding: No funding was received for this research

Conflicts of interest: All authors certify that they have no affiliations with or involvement in any organization or entity with any financial interest (such as honoraria; educational grants; participation in speakers' bureaus; membership, employment, consultancies, stock ownership, or other equity interest; and expert testimony or patent-licensing arrangements), or non-financial interest (such as personal or professional relationships, affiliations, knowledge or beliefs) in the subject matter or materials discussed in this manuscript.

Availability of data and material: data were available if necessary

Ethics approval: All procedures performed in studies involving human participants were in accordance with the ethical standards of the institutional Ethics of French College of Neurosurgery (showed in appendix) and with the 1964 Helsinki declaration and its later amendments or comparable ethical standards.

Consent to participate: not applicable, for this type of study formal consent is not required

Consent for publication: not applicable

Authors' contributions: not applicable

\section{References}

1. Adams KB, Roberts AR, Cole MB (2011) Changes in activity and interest in the third and fourth age: associations with health, functioning and depressive symptoms. Occup Ther Int 18(1):4-17

2. Balabaud L, Pitel S, Caux I, Dova C, Richard B, Antonietti P, Mazel C (2015) Lumbar spine surgery in patients 80 years of age or older: morbidity and mortality. Eur J Orthop Surg Traumatol 25 Suppl 1:S205-212

3. Blumenthal C, Curran J, Benzel EC, Potter R, Magge SN, Harrington JF, Coumans J-V, Ghogawala Z (2013) Radiographic predictors of delayed instability following decompression without fusion for degenerative grade I lumbar spondylolisthesis. J Neurosurg Spine 18(4):340-346

4. Bono OJ, Poorman GW, Foster N, et al (2018) Body mass index predicts risk of complications in lumbar spine surgery based on surgical invasiveness. Spine J 18(7):1204-1210

5. Chad DA (2007) Lumbar spinal stenosis. Neurol Clin 25(2):407-418

6. Chaló D, Pedrosa S, Amorim P, Gouveia S, Sancho C (2020) Propofol TCI Reductions Do Not Attenuate Significant Falls in Cardiac Output Associated With Anesthesia Induction and Knee-Chest Positioning in Spinal Surgery. J Neurosurg Anesthesiol 32(2):147-155

7. Charlson ME, Pompei P, Ales KL, MacKenzie CR (1987) A new method of classifying prognostic comorbidity in longitudinal studies: development and validation. J Chronic Dis 40(5):373-383

8. Debono B, Wainwright TW, Wang MY, et al (2021) Consensus statement for perioperative care in lumbar spinal fusion: Enhanced Recovery After Surgery (ERAS $\left.{ }^{\circledR}\right)$ Society recommendations. The Spine Journal 21(5):729-752

9. Deyo RA, Mirza SK, Martin BI, Kreuter W, Goodman DC, Jarvik JG (2010) Trends, major medical complications, and charges associated with surgery for lumbar spinal stenosis in older adults. JAMA 303(13):1259-1265

10. Elsamadicy AA, Adogwa O, Vuong VD, Mehta Al, Vasquez RA, Cheng J, Karikari IO, Bagley CA (2016) Patient Body Mass Index is an Independent Predictor of 30-Day Hospital Readmission After Elective Spine Surgery. World Neurosurgery 96:148-151

11. Fineberg SJ, Nandyala SV, Marquez-Lara A, Oglesby M, Patel AA, Singh K (2013) Incidence and risk factors for postoperative delirium after lumbar spine surgery. Spine (Phila Pa 1976) 38(20):1790-1796

Page 13/16 
12. Försth P, Ólafsson G, Carlsson T, Frost A, Borgström F, Fritzell P, Öhagen P, Michaëlsson K, Sandén B (2016) A Randomized, Controlled Trial of Fusion Surgery for Lumbar Spinal Stenosis. New England Journal of Medicine 374(15):1413-1423

13. Gerhardt J, Bette S, Janssen I, Gempt J, Meyer B, Ryang Y-M (2018) Is Eighty the New Sixty? Outcomes and Complications after Lumbar Decompression Surgery in Elderly Patients over 80 Years of Age. World Neurosurg 112:e555-e560

14. Ghasem A, Sharma A, Greif DN, Alam M, Maaieh MA (2018) The Arrival of Robotics in Spine Surgery: A Review of the Literature. Spine (Phila Pa 1976) 43(23):1670-1677

15. Giannadakis C, Nerland US, Solheim O, Jakola AS, Gulati M, Weber C, Nygaard ØP, Solberg TK, Gulati S (2015) Does Obesity Affect Outcomes After Decompressive Surgery for Lumbar Spinal Stenosis? A Multicenter, Observational, Registry-Based Study. World Neurosurg 84(5):1227-1234

16. Giannadakis C, Solheim O, Jakola AS, Nordseth T, Gulati AM, Nerland US, Nygaard ØP, Solberg TK, Gulati S (2016) Surgery for Lumbar Spinal Stenosis in Individuals Aged 80 and Older: A Multicenter Observational Study. J Am Geriatr Soc 64(10):2011-2018

17. Glotzbecker MP, Bono CM, Wood KB, Harris MB (2010) Postoperative spinal epidural hematoma: a systematic review. Spine (Phila Pa 1976) 35(10):E413-420

18. Jackson KL, Devine JG (2016) The Effects of Smoking and Smoking Cessation on Spine Surgery: A Systematic Review of the Literature. Global Spine J 6(7):695-701

19. Kalichman L, Cole R, Kim DH, Li L, Suri P, Guermazi A, Hunter DJ (2009) Spinal stenosis prevalence and association with symptoms: the Framingham Study. Spine J 9(7):545-550

20. Kalichman L, Kim DH, Li L, Guermazi A, Berkin V, Hunter DJ (2009) Spondylolysis and spondylolisthesis: prevalence and association with low back pain in the adult community-based population. Spine (Phila Pa 1976) 34(2):199-205

21. Kay HF, Chotai S, Wick JB, Stonko DP, McGirt MJ, Devin CJ (2016) Preoperative and surgical factors associated with postoperative intensive care unit admission following operative treatment for degenerative lumbar spine disease. Eur Spine J 25(3):843-849

22. Kazarian ER, Lopez WY, Eizember S, Blucher JA, Culley DJ, Javedan H, Kang JD, Schoenfeld AJ (2020) Incidental Durotomy Is Associated With Increased Risk of Delirium in Patients Aged 65 and Older. Spine (Phila Pa 1976) 45(17):1215-1220

23. Kim J-E, Choi D-J, Park EJ (2020) Risk Factors and Options of Management for an Incidental Dural Tear in Biportal Endoscopic Spine Surgery. Asian Spine J 14(6):790-800

24. Knutsson B, Sandén B, Sjödén G, Järvholm B, Michaëlsson K (2015) Body Mass Index and Risk for Clinical Lumbar Spinal Stenosis: A Cohort Study. Spine (Phila Pa 1976) 40(18):1451-1456

25. Kong C, Li X, Sun X, Ding J, Guo M, Lu S (2019) Complications in Elderly Patients Undergoing Lumbar Arthrodesis for Spinal Stenosis. World Neurosurg 132:e949-e955

26. Kreiner DS, Shaffer WO, Baisden J, Gilbert T, Summers J, Toton J, Hwang S, Mendel R, Reitman C Diagnosis and Treatment of Degenerative Lumbar Spinal Stenosis. 104

27. Kreiner DS, Shaffer WO, Baisden JL, Gilbert TJ, Summers JT, Toton JF, Hwang SW, Mendel RC, Reitman CA, North American Spine Society (2013) An evidence-based clinical guideline for the diagnosis and treatment of degenerative lumbar spinal stenosis (update). Spine $J$ 13(7):734-743

28. Lee CK, Choi SK, Shin DA, Yi S, Ha Y, Kim KN, Kim I (2019) Influence of diabetes mellitus on patients with lumbar spinal stenosis: A nationwide population-based study. PLoS One 14(3):e0213858

29. Li G, Patil CG, Lad SP, Ho C, Tian W, Boakye M (2008) Effects of age and comorbidities on complication rates and adverse outcomes after lumbar laminectomy in elderly patients. Spine (Phila Pa 1976) 33(11):1250-1255

30. Masson E Traitement chirurgical des sténoses du canal lombaire. In: EM-Consulte. https://www.emconsulte.com/article/56019/traitement-chirurgical-des-stenoses-du-canal-lomba. Accessed 14 Jul 2021

31. Morcos MW, Jiang F, Mclntosh G, et al (2018) Predictors of Blood Transfusion in Posterior Lumbar Spinal Fusion: A Canadian Spine Outcome and Research Network Study. Spine (Phila Pa 1976) 43(1):E35-E39

32. Murphy ME, Gilder H, Maloney PR, et al (2017) Lumbar decompression in the elderly: increased age as a risk factor for complications and nonhome discharge. J Neurosurg Spine 26(3):353-362

33. Nanjo Y, Nagashima H, Dokai T, et al (2013) Clinical features and surgical outcomes of lumbar spinal stenosis in patients aged 80 years or older: a multi-center retrospective study. Arch Orthop Trauma Surg 133(9):1243-1248

34. Otani K, Kikuchi S, Yabuki S, Igarashi T, Nikaido T, Watanabe K, Konno S (2013) Lumbar Spinal Stenosis Has a Negative Impact on Quality of Life Compared with Other Comorbidities: An Epidemiological Cross-Sectional Study of 1862 Community-Dwelling Individuals. ScientificWorldJournal. doi: 10.1155/2013/590652

35. Otani K, Kikuchi S, Yabuki S, Igarashi T, Nikaido T, Watanabe K, Konno S (2013) Lumbar spinal stenosis has a negative impact on quality of life compared with other comorbidities: an epidemiological cross-sectional study of 1862 community-dwelling individuals.

Page $14 / 16$ 
ScientificWorldJournal 2013:590652

36. Park JH, Park S, Choi SA (2020) Incidence and risk factors of spinal epidural hemorrhage after spine surgery: a cross-sectional retrospective analysis of a national database. BMC Musculoskelet Disord 21:324

37. Pernik MN, Deme PR, Nguyen ML, et al (2021) Perioperative Optimization of Senior Health in Spine Surgery: Impact on Postoperative Delirium. J Am Geriatr Soc 69(5):1240-1248

38. Phan K, Mobbs RJ (2016) Minimally Invasive Versus Open Laminectomy for Lumbar Stenosis: A Systematic Review and Meta-Analysis. Spine 41(2):E91-E100

39. Rigamonti A, Gemma M, Rocca A, Messina M, Bignami E, Beretta L (2005) Prone versus knee-chest position for microdiscectomy: a prospective randomized study of intra-abdominal pressure and intraoperative bleeding. Spine (Phila Pa 1976) 30(17):1918-1923

40. Rodríguez-Mañas L, Féart C, Mann G, et al (2013) Searching for an Operational Definition of Frailty: A Delphi Method Based Consensus Statement. The Frailty Operative Definition-Consensus Conference Project. J Gerontol A Biol Sci Med Sci 68(1):62-67

41. Rudolph C, Schaffranietz L, Hellmundt L, Vitzthum HE, Olthoff D (2002) [Comparative studies of patient positioning for lumbar intervertebral disk operation]. Anaesthesiol Reanim 27(2):38-41

42. Saleh A, Thirukumaran C, Mesfin A, Molinari RW (2017) Complications and readmission after lumbar spine surgery in elderly patients: an analysis of 2,320 patients. Spine $\mathrm{J} 17(8): 1106-1112$

43. Sharif S, Shaikh Y, Bajamal AH, Costa F, Zileli M (2020) Fusion Surgery for Lumbar Spinal Stenosis: WFNS Spine Committee Recommendations. World Neurosurg X 7:100077

44. Shriver MF, Zeer V, Alentado VJ, Mroz TE, Benzel EC, Steinmetz MP (2015) Lumbar spine surgery positioning complications: a systematic review. Neurosurg Focus 39(4):E16

45. Simcox T, Antoku D, Jain N, Acosta F, Hah R (2019) Frailty Syndrome and the Use of Frailty Indices as a Preoperative Risk Stratification Tool in Spine Surgery: A Review. Asian Spine J 13(5):861-873

46. Soleman J, Baumgarten P, Perrig WN, Fandino J, Fathi A-R (2016) Non-instrumented extradural lumbar spine surgery under low-dose acetylsalicylic acid: a comparative risk analysis study. Eur Spine J 25(3):732-739

47. Strömqvist F, Sigmundsson FG, Strömqvist B, Jönsson B, Karlsson MK (2019) Incidental durotomy in degenerative lumbar spine surgery - a register study of 64,431 operations. Spine J 19(4):624-630

48. Takahashi Y, Sato T, Hyodo H, Kawamata T, Takahashi E, Miyatake N, Tokunaga M (2013) Incidental durotomy during lumbar spine surgery: risk factors and anatomic locations: clinical article. J Neurosurg Spine 18(2):165-169

49. Tsantes AG, Papadopoulos DV, Lytras T, et al (2020) Association of malnutrition with surgical site infection following spinal surgery: systematic review and meta-analysis. J Hosp Infect 104(1):111-119

50. Wang MY, Widi G, Levi AD (2015) The safety profile of lumbar spinal surgery in elderly patients 85 years and older. Neurosurg Focus 39(4):E3

51. Weinstein JN, Tosteson TD, Lurie JD, et al (2008) Surgical versus nonsurgical therapy for lumbar spinal stenosis. N Engl J Med 358(8):794-810

52. Yao R, Zhou H, Choma TJ, Kwon BK, Street J (2018) Surgical Site Infection in Spine Surgery: Who Is at Risk? Global Spine J 8(4 Suppl):5S$30 \mathrm{~S}$

53. Yoshioka K, Murakami H, Demura S, Kato S, Tsuchiya H (2015) Prevalence and risk factors for development of venous thromboembolism after degenerative spinal surgery. Spine (Phila Pa 1976) 40(5):E301-306

54. Zaina F, Tomkins-Lane C, Carragee E, Negrini S (2016) Surgical versus non-surgical treatment for lumbar spinal stenosis. Cochrane Database Syst Rev 2016(1):CD010264

55. Zhang L, Li E-N (2018) Risk factors for surgical site infection following lumbar spinal surgery: a meta-analysis. Therapeutics and Clinical Risk Management 14:2161

56. (2017) Gestion du patient diabétique en périopératoire. Fiches pratiques. Anesthésie \& Réanimation 3(3):263-300

57. Bilan démographique 2020 - Insee Première - 1834. https://www.insee.fr/fr/statistiques/5012724\#figure6_radio2. Accessed 14 Jul 2021

58. Le vieillissement démographique en Normandie à l'horizon 2050 : une forte poussée des populations dépendantes à partir de 2030 - Insee Flash Normandie - 65. https://www.insee.fr/fr/statistiques/3574506.

59. La dépendance des personnes âgées: une projection en 2040 - Données sociales: La société française | Insee. https://www.insee.fr/fr/statistiques/1371933?sommaire=1372045. Accessed 14 Jul 2021

60. MCO par diagnostic ou acte I Stats ATIH. https://www.scansante.fr/applications/statistiques-activite-MCO-par-diagnostique-etactes/submit? snatnav $=\&$ snatdoc $=\&$ mbout $=\&$ annee=2019\&base=deux\&typt=cim\&code=M4806\&ok=Lancer+le+traitement $\&$ niveau=0 $\&$ codh $=0000000000$.

Page 15/16 
61. Predictors of unplanned readmission in patients undergoing lumbar decompression: multi-institutional analysis of 7016 patients PubMed. https://pubmed.ncbi.nlm.nih.gov/24725183/. Accessed 9 Sep 2021

62. fiche_memo_note_de_cadrage_hta_cd_20150723_vd.pdf.

63. Preoperative Nutritional Status is an Independent Predictor...: Spine. https://journals.Iww.com/spinejournal/Abstract/2016/09010/Preoperative_Nutritional_Status_is_an_Independent.19.aspx. Accessed 6 Sep 2021

64. CT-12342_EXACYL_avis2_RI_reevalSMR_CT12342.pdf.

\section{Figures}

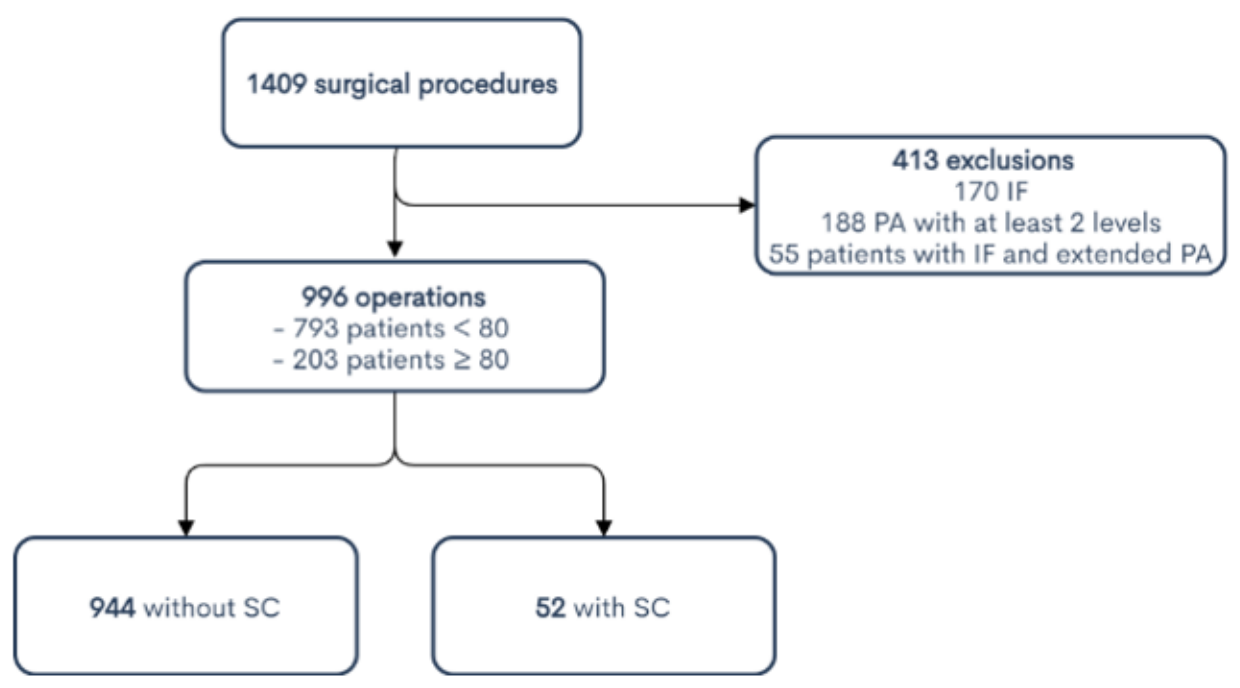

\section{Figure 1}

Flowchart IF, interbody fusion; PA, posterolateral arthrodesis

\section{Supplementary Files}

This is a list of supplementary files associated with this preprint. Click to download.

- floatimage5.jpeg 